\title{
Beaming the laser into the home
}

Christopher Whitehead

Journal of Laser Applications. Editor-in-chief Sidney S. Charschan. Chapman and Hall. 4/yr. USA and Canada \$159, Europe £110, elsewhere $£ 125$ (institutional).

THIS year is the thirty-fifth birthday of the laser. Far from being a scientific curiosity in its infancy, the device is now approaching the staid respectability of middle age and the associated responsibility of having to work for its living. Lasers are now widely used in many areas of science, engineering, medicine and manufacturing and are even commonplace in the home; anyone who has a CD player or a CD-ROM drive owns a laser. A journal devoted to applications of lasers might seem to be overdue. Journal of Laser Applications is the official journal of the Laser Institute of America (and is free to members) and was started in October 1988 as "the major forum for cross-fertilisation of ideas in disciplines applying laser technologies". In 1994, Chapman and Hall began to publish a revamped version of the journal to "expand its circulation into a wider international market”. Four issues are now published a year.

Each issue has an introductory section with a leading article, reports and information of direct interest to members of the Laser Institute. The rest contains invited overview articles, book reviews and submitted papers that are subject to peer review. There are about 10 articles in each issue with publication times of 3-6 months. Articles are accompanied by figures (often poorly reproduced) and photographs (in monochrome). Wisely, the editorial policy of the journal is to concentrate on certain definite areas of laser applications. These declared areas are materials processing, medicine, surgery and bioeffects, sensing, measurement and control, and laser safety. Inevitably, most contributions come from the United States but there is a significant number of articles from workers in Japan and Europe. Articles dealing with materials processing are in the majority. The Laser Institute is keen to promote safe practice in the use of lasers and the journal serves a useful purpose in bringing articles on laser safety to the attention of the user community in a way not possible for similar articles published in journals devoted to safety and occupational health. There is also an interest in the use of lasers in education and most issues have papers under the theme of "Applying Lasers in the Classrooms". These form a particularly useful collection of articles for teachers and lecturers concerned with developing practical classes involving lasers.

The journal's style is reminiscent of Applied Optics, published by the Optical Society of America, although Applied
Optics has a much wider coverage than just laser applications. Journal of Laser Applications generally contains two or three articles of interest in each issue, so it is well worth looking at in the library. It certainly fills a gap by publishing papers on laser safety, lasers in education and general review articles, but I doubt

IMAGE
UNAVAILABLE
FOR COPYRIGHT
REASONS

Light work: surgeon with laser torch.

whether leading international researchers using lasers in materials processing or medicine, say, will ever submit their firstrank contributions to the journal. The support of the Laser Institute will probably ensure its survival, and institutions with significant numbers of laser users might well contemplate taking out a subscription.

Christopher Whitehead is in the Department of Chemistry, University of Manchester, Manchester M13 9PL, UK.

\section{Surface active}

\section{David King}

Surface Review and Letters. Editor-inchief S. Y. Tong. World Scientific. 6/yr. $\$ 390$ (institutional); $\$ 190$ (institutions in developing countries); $\$ 120$ (personal).

Interface Science. Editor-in-chief David J. Srolovitz. Kluwer. 4/yr. \$216, Dfl414 (institutional); $\$ 95, £ 225$ (personal).

Tribology Letters. Editors-in-chief Nicholas D. Spencer and Wilfred T. Tysoe. Baltzer. 4/yr. Sfr354.

IT is hardly a surprise that these three new specialist journals dealing with solid surfaces should be launched now. They all lie within the general area covered by the journal Surface Science, launched by Elsevier in 1963 and considered at the time to be a highly specialized journal in a fledgling field of science bordering on physics, chemistry, materials science and engineering. It proved to be a resounding success, recently given a triumphal celebration by the publishers with the appearance last year of a special volume, "Surface Science: The First Thirty Years". This period marked the development of the field from a qualitative, macroscopically based subject to one based on a detailed knowledge of surface atomic geometries, dynamics and electronic charge distribution. These developments have come hand-in-hand with major transformations in commercially important technologies, $\vec{a} \hat{\omega}$ particularly in the manufacture of microelectronics but also in the manufacture of new materials generally, including the design of catalysts. The worldwide impact has been enormous and it is my view that the journal itself has played an important role by providing a focus for this activity.

In its first full year of publication, 1964, Surface Science ran to 574 pages. By last year this had risen to 8,600 pages, and Elsevier had brought out two companion journals, Applied Surface Science and Surface Science Reports. The journal Langmuir, published by the American Chemical Society, covering the broader field of surfaces and colloids, had also been successfully launched.

Surface Review and Letters must be seen as a direct competitor to Surface Science. As Elsevier is, alas, a notoriously expensive publisher, and World Scientific seems to be capable of undercutting it, this is a welcome move. The coverage in the first year of operation, running to 700 pages, meets the editor's stated objective to include both the physical and the chemical properties of surfaces and interfaces. But because both the editor and his associate editor, Dilano Saldin, hail from a physics department and the board of editors is very heavily biased towards physics, it will be interesting to see whether the essentially interdisciplinary character of the field can be fully represented. There is also among members of the board an undue emphasis on structural determination; although this will continue to be a crucially important aspect of surface studies, the field of chemical reaction dynamics at surfaces is the real growth area in this field. The journal is well produced, and it will be interesting to see if it does emerge as a commercial success.

Interface Science is narrower in scope, being clearly aimed at the properties of solid-solid interfaces. The editor and his board are primarily drawn from the field of materials science. Apart from the journals described above, the main competitors are Philosophical Magazine, Ultramicroscopy and Journal of Crystal Growth. I believe that the publishers have marked 